\title{
Functionalized Gold Nanoparticles improve Afatinib delivery into Cancer cells
}

Sílvia Castro Coelho ${ }^{1,{ }^{*}}$, Gabriela M. Almeida ${ }^{2,3}$, Maria Carmo Pereira ${ }^{1}$, Filipe Santos-Silva ${ }^{2,4,5,6}$, Manuel A.N. Coelho ${ }^{1}$

(1) LEPABE, Department of Chemical Engineering, Faculty of Engineering, University of Porto, Portugal

(2) Instituto de Investigação e Inovação em Saúde, Universidade do Porto, Portugal

(3) Expression Regulation in Cancer Group, IPATIMUP, Porto, Portugal

(4) Public Awareness of Cancer Unit, IPATIMUP, Porto, Portugal

(5) Faculty of Medicine, University of Porto, Porto, Portugal,

(6) Department of Biochemistry and Molecular Biology, Eppley Institute, University of Nebraska Medical Center, Omaha, USA

* corresponding author: Sílvia Castro Coelho, LEPABE, Department of Chemical Engineering, Faculty of Engineering, University of Porto, Rua Roberto Frias, PT-4200-465 Porto, Portugal. Phone: +351 225081679; Fax: +351 225081449; E-mail: silvia.coelho@fe.up.pt

Objectives: A drug delivery system based on colloidal pegylated gold nanoparticles (PEGAuNPs) conjugated with the tyrosine kinase inhibitor afatinib was designed and tested for enhancing the drug activity against pancreatic and non-small cell lung cancer cells.

Methods: PEGAuNPs were synthesized and characterized physicochemically. Confocal imaging was performed to evaluate the nanoparticle internalization in cancer cells. For cell cycle distribution analysis, conjugated nanoparticles and afatinib alone were incubated with cells and alterations on the cell cycle profile subsequently analyzed by total DNA staining. Cancer cell survival and growth inhibition following incubation with afatinib and PEGAuNPs-afatinib (concentrations between 0.007 and $0.500 \mu \mathrm{M}$ afatinib) were evaluated. Results: A higher cellular uptake of PEGAuNPs was observed by cancer cells. Our data suggest an efficient conjugation of PEGAuNPs with the drug, enhancing the afatinib activity in comparison with afatinib alone. In fact, $\mathrm{IC}_{50}$ and $\mathrm{GI}_{50}$ results obtained show that the PEGAuNPs-afatinib conjugate is ca. 5 and 20 times more potent than afatinib alone in S2-013 and A549 cell lines, respectively.

Conclusions: Conjugating PEGAuNPs with afatinib is a promising antitumour delivery system for cancer therapy as it improves drug efficacy, allowing to decrease the dose of drug used and minimizing possible toxicity related side effects.

Keywords: irreversible covalent inhibitor of the receptor tyrosine, gold nanoparticles, pancreatic cancer cells, non-small cell lung cancer, afatinib 


\section{Introduction}

Nanoparticles (NPs) have been considered an elective vector for targeted therapies, with expanding applications in medical nanotechnology [1-4]. They are able to cross biological barriers and enter the cells, driven by the enhanced permeability and retention (EPR) of NPs in the tumour $[5,6]$. Several studies revealed the influence of NPs physico-chemical characteristics and cell cycle phase on internalization process $[7,8]$. Using a nanoparticle vector' inherent surface chemistry, a combination of targeting, imaging, therapeutic applications and, even photothermal or radiosensitizing therapies can be involved [8].

Currently, gold nanoparticles (AuNPs) have been presented as drug-loaded nanocarriers, which remains one of the most promising drug delivery systems (DDS) to be used for cancer therapies and diagnosis [9-12]. AuNPs have unusual and distinguish properties, being biocompatible and able to be coated with biocompatible polymers conferring them adequate surface charge, and stability [13-15]. The coupling of anticancer drugs to colloidal gold nanoparticles is a possible strategy once it is very important to ensure the activity of the drugs and the viability of the nanosystem (linkage stability) [16]. AuNPs can protect and decrease the antitumour drug dose to be administered to cancer patients (whilst increasing the drug dose being delivered into cancer cells), hence diminishing possible chemotherapy side effects [17].

Several studies investigating AuNPs related toxicity in cancer cells, have reported that they do not present significant toxicity $[15,18-20]$. Also, studies have shown that AuNPs are internalized by endocytosis process $[8,21,22]$. AuNPs present small sizes and are able to penetrate and accumulate at tumour sites through EPR effect [8]. They can improve the drug ability for tumour penetration and overcome the multidrug resistance (MDR) problem of solid tumours [23].

Afatinib, also known as BIBW2992 ((E)-N-[4-(3-chloro-4-fluoro-anilino)-7-[(3S)-tetrahydrofuran-3-yl]oxyquinazolin-6-yl]-4-(dimethylamino)but-2-enamide) is an aniline-quinazoline that irreversibly binds to the intracellular tyrosine kinase domain of the ErbB family of receptors (acting as a pan-ErbB inhibitor) [24-26]. Upon binding to ErbB, afatinib blocks the signaling from homo and heterodimers inhibiting cell growth and inducing apoptosis in cancer cells. Afatinib is one of the agents approved for the treatment of non-small cell lung cancer (NSCLC) due to its antitumour effect [27, 28]. Indeed, afatinib has been approved for first-line treatment of patients with metastatic NSCLC, whose tumours have specific mutations in EGFR, namely exon 19 deletions or exon 21 (L858R) substitutions [29]. Some reports also suggest that afatinib can be a promising inhibitor against human pancreatic tumour cells [24, 30, 31]. Positive results have also been reported in the 
therapy of other advanced solid tumours, when afatinib is given in combination with conventional chemotherapeutic agents $[26,32]$. In this study, we assessed in vitro the effect of afatinib conjugated with PEGAuNPs in pancreatic cancer cells (cell line S2-013), and NSCLC cells (cell line A549). Our aim is to enhance the effect of afatinib on cancer cells using PEGAuNPs. The nanoparticle system designed was characterized regarding particle size, stability, drug release and cytotoxicity. Our results reinforce that afatinib uptake and cell toxicity in pancreatic and lung cancer cells can be enhanced by conjugating afatinib with PEGAuNPs.

\section{Materials and methods}

\section{Chemicals}

Afatinib (BIBW2992) was purchased from Selleck Chemicals LLC (USA); fetal bovine serum (FBS), phosphate buffered saline (PBS), trypsin, Dulbecco's modified Eagle's medium (DMEM) and RPMI 1640 medium were obtained from Invitrogen Co. (Scotland, UK). Acetic acid, dimethyl sulfoxide (DMSO), sulforhodamine B (SRB), trypan blue, trisodium citrate dehydrate, tetrachloroauric (III) acid (HAuCl4; 99.99\% trace metals basis, $30 \mathrm{wt} \%$ in dilute $\mathrm{HCl}$, N-ethyl-N'-(3-dimethylaminopropyl) cabodiimide (EDC), SulfoNHS (N-hydroxysulfosuccinimide) and propidium iodide were purchased from Sigma-Aldrich (Germany). Tricloroacetic acid (TCA) and Tris buffer were acquired from Merck (Darmstadt, Germany). a-thiol-wcarboxyl (polyethylene glycol) (HS-PEG-COOH; molecular weight 394.57 Da) was purchased from Prochimia (Poland).

\section{Cell lines}

The pancreatic cell lines, S2-013 (well differentiated tubular adenocarcinoma and moderately metastatic subline cloned from the human pancreatic tumor cell line SUIT-2) was kindly provided by Prof. M. A. Hollingsworth (Eppley Institute for Research in Cancer and Allied Diseases, UNMC, Omaha, NE, USA). Adherent cell cultures were maintained in DMEM with $10 \%$ heat-inactivated FBS at $37^{\circ} \mathrm{C}$ in a humidified atmosphere of $5 \% \mathrm{CO}_{2}$ incubator.

The non-small cell lung cancer cell line (A549) was a kind gift from Dr George DD Jones (University of Leicester, UK). A549 cells were grown as a monolayer in RPMI 1640 media with 10\% heat-inactivated FBS at $37^{\circ} \mathrm{C}$ in a humidified atmosphere of $5 \% \mathrm{CO}_{2}$. 
AuNPs were synthesized by the Turkevitch method $[33,34]$. Briefly tetrachloroauric acid $\left(\mathrm{HAuCl}_{4}\right)$ was reduced with trisodium citrate. HAuCl4 aqueous solution was heated to slight boiling and stirred. Trisodium citrate was added and boiled for $15 \mathrm{~min}$. Then, AuNPs were pegylated (PEGAuNPs) with thiolated poly(ethylene glycol) layer (PEG) capped with a carboxylate group with a molar ratio 1:1,000, respectively. The mixture was stirred at room temperature for about $1 \mathrm{~h}$. The resultant solution was centrifuged at $13,400 \times$ $\operatorname{rpm}(12,000 \times \mathrm{g})$ during $10 \mathrm{~min}$ to remove the unbound PEG molecules. The concentration of the PEGAuNPs was $14.02 \mathrm{nM}$ as determined by the Lambert-Beer Law assuming the molar absorptivity of the AuNPs plasmon resonance band at $526 \mathrm{~nm}$ being $2.33 \times 10^{8} \mathrm{M}^{-1} \mathrm{~cm}^{-1}$.

\section{Conjugation of afatinib to PEGAUNPS}

To prepare the afatinib conjugated to pegylated gold nanoparticles, we used EDC/NHSS coupling that can bind covalently with carboxyl groups of PEGAuNPs and amine groups of afatinib. The molar ratio PEGAuNPs:afatinib is 1:1540. The solution was stirred at room temperature for $1 \mathrm{~h}$. The final solution was centrifuged at 13,400 rpm during 10 min to remove the unbound antitumour drug.

\section{Dynamic light scattering and electrophoretic mobility measurements}

Size distribution and zeta potential of the nanoparticles was analyzed by dynamic light scattering (DLS) and laser Doppler velocimetry, respectively, by a Zetasizer Nano ZS (Malvern Instruments Ltd., Malvern, UK), at $25^{\circ} \mathrm{C}$. Size measurements were performed at a scattering angle of 173 in a $12 \mathrm{~mm}$ square polystyrene cuvette (Sarstedt, Germany). The zeta potential was obtained by using a disposable capillary cell (DTS 1060, Malvern).

\section{UV-VIS spectroscopy}

The UV-VIS absorption spectra of the PEGAuNPs and PEGAuNPs-afatinib were measured in a $1 \mathrm{~cm}$ quartz cuvette at room temperature using a Shimadzu UV-1700 PharmaSpec spectrophotometer.

Attenuated Total Reflectance-Fourier Transform Infrared Spectroscopy (ATR-FTIR)

The PEGAuNPs-afatinib, PEGAuNPs and afatinib solutions were analysed and ATR-FTIR spectra were recorded with an ALPHA FTIR Spectrometer (Bruker) in the spectral range 4,000-400 $\mathrm{cm}^{-1}$, resolution of 4 $\mathrm{cm}^{-1}$ and 64 scans, at room temperature.

\section{Assay of Protein Tyrosine Kinase}

Afatinib activity was studied with Tyrosine Kinase Assay as described in the Universal Tyrosine Kinase assay kit (TAKARA). This kit enables the analysis of the regulation of PTK activity. It was measured the Protein Tyrosine Kinase (PTK) activity in a specific range of concentrations of 0.5 to $15 \mu \mathrm{M}$ by its absorbance at 450 
nm using a microplate reader (PowerWave HT Microplate Spectrophotometer, BioTek), in order to determine the afatinib calibration curve. To determine the encapsulation efficiency of afatinib from PEGAuNPs, it was measured the PTK activity of the supernatant after conjugation of afatinib with PEGAuNPs.

\section{In vitro drug release studies}

The drug release study of PEGAuNPs-afatinib was carried out at $37^{\circ} \mathrm{C}$ by dialysis using a regenerated cellulose membrane with an initial afatinib concentration of $4.1 \mu \mathrm{M}$. The solutions were incubated in $6 \mathrm{~mL}$ of PBS 0.01 M, with constant magnetic stirring. It was obtained a significant afatinib concentration into PEGAuNPs and, then, the afatinib concentration of the dialysate buffer could be analyzed, with time, using spectrophotometric analysis at $247 \mathrm{~nm}$ (the concentration is under the limit of detection of the Shimadzu UV-1700 PharmaSpec spectrophotometer).

\section{Cellular imaging studies}

Imaging experiments were performed with the S2-013 and A549 cells. About 800 cells per well were grown for $24 \mathrm{~h}$ in a $\mu$-chamber 12 -well plates (ibidi, Germany) under normal conditions $\left(5 \% \mathrm{CO}_{2}\right.$ humidified atmosphere at $37^{\circ} \mathrm{C}$ ). The cells were incubated with $1.0 \mathrm{nM}$ of PEGAuNPs for 2 hours. Following the incubation, the cells were rinsed with $1 \%$ of phosphate buffered saline (PBS) and fixed using 4\% paraformaldehyde for $15 \mathrm{~min}$. The cells were washed with PBS and mounted in a glycerol-based non-drying and non-hardening medium. Imaging was performed using a laser scanning confocal microscope (LSCM) TCS SP5 II (Leica Microsystems, Germany). To evaluate the nanoparticle internalization in the cells, the control untreated cells were also imaged. Different areas were analyzed and at least three images were acquired for each type of cell.

\section{Flow cytometer assays}

For cell cycle distribution analysis, samples were seeded with $1 \times 10^{5}$ cells in $1 \mathrm{~mL}$ and grown for 72 hours. Conjugated nanoparticles were prepared freshly under sterile conditions. After incubation with nanoparticles and afatinib alone, cells were washed, pelleted, and resuspended in PBS (pH 7.4). Cells were then stained with DNA-binding dye propidium iodide (PI) immediately before flow cytometry (FACS Calibur, BD Biosciences, San Jose, CA, USA). Three independent experiments were carried out, including untreated controls. Flow cytometer assays were performed plotting at least 15,000 events per sample and data were subsequently analyzed by FlowJo 10.0.7 software (Tree Star, Ashland, USA. Alterations to the normal cell cycle profile after samples exposure was studied by total DNA staining. 
The effects of the nanoparticles and drug on cell growth were evaluated by the Sulforhodamine B (SRB) assay (colorimetric) as previously described [9].

Briefly, S2-013 and A549 cells were seeded in 96-well plates (1,000 cells per well) under normal conditions $\left(5 \% \mathrm{CO}_{2}\right.$ humidified atmosphere at $37^{\circ} \mathrm{C}$ ) and allowed to adhere for $20-24 \mathrm{~h}$. The cells were then incubated with afatinib, PEGAuNPs or PEGAuNPs-afatinib at the concentrations ranging between 0.007 and $0.500 \mu \mathrm{M}$ afatinib. Following this incubation period, the cells were fixed with $10 \%$ TCA for $1 \mathrm{~h}$ on ice, washed and stained with $50 \mu \mathrm{L} 0.4 \% \mathrm{SRB}$ dye for $30 \mathrm{~min}$. The cells were then washed repeatedly with $1 \%$ acetic acid to remove unbound dye. The cells were dried and the protein-bound stain was solubilized with $10 \mathrm{mM}$ Tris solution.

The SRB absorbance was measured at $560 \mathrm{~nm}$ using the PowerWave microplate reader. The concentration that inhibits cell survival in 50\% $\left(\mathrm{IC}_{50}\right)$ and the concentration that inhibits cell growth in $50 \%\left(\mathrm{GI}_{50}\right)$ were determined using the SRB assay. The absorbance of the wells containing the nanoparticles or drug and the absorbance of the wells containing untreated cells following a $72 \mathrm{~h}$ incubation period were subsequently compared with that of the wells containing the cells that had been fixed at time zero (when the nanoparticles and drug were added).

\section{Statistical analysis}

At least three independent experiments were performed for each assay. Statistical significance $(\mathrm{p}<0.05)$ was determined by the Student's t-Test.

\section{Results and Discussion}

The citrate-stabilized AuNPs ( $\mathrm{pH}$ of 5.1) were prepared and functionalized covalently with a hydrophilic polymer polyethylene glycol as a spacer. The average hydrodynamic diameter of PEGAuNPs (pH of 5.3) measured by DLS is $41 \pm 1 \mathrm{~nm}$ with a low polydispersity index, indicating uniform nanoparticles (Table 1). NPs present high stability as shown by $-39 \mathrm{mV}$ of zeta potential. Also, PEGAuNPs are stable for at least 6 months at $4{ }^{\circ} \mathrm{C}$ and in the dark. The covalently linked bioconjugates of PEGAuNPs and afatinib (PEGAuNPs-afatinib) were prepared through the coupling reaction of EDC/NHSS [35]. EDC reacted with the carboxylate groups forming an active ester (o-acylisourea) leaving group [35]. Then, from the reaction of the hydroxyl group on sulfo-NHS with EDC active-ester complex, a highly reactive sulfo-NHS-ester complex intermediate was formed [35]. The NHS-terminated AuNPs were mixed with afatinib solution, the side chains amino groups of 
the afatinib displaced the terminal NHS groups of PEGAuNPs. PEGAuNPs-afatinib obtained through covalent bounds do not significantly change their size and zeta potential changed to $-35 \mathrm{mV}$ (Table 1). Figure 1 shows the UV-vis spectra of NPs. The surface plasmon resonance (SPR) of PEGAuNPs is around $522 \mathrm{~nm}$ in water, typical of AuNPs, and their estimated concentration, determined by the Lambert-Beer Law, was $14.02 \mathrm{nM}[15$, 36]. In the presence of afatinib, it is possible to visualize the afatinib peaks at 247 and $341 \mathrm{~nm}$.

In order to confirm the covalent bonds, we conducted the FTIR analysis of NPs. Figure 2 shows the ATR-FTIR spectra of modified PEGAuNPs. The distinct peaks of PEGAuNPs appeared at $1742 \mathrm{~cm}^{-1}$ from carbonyl groups of terminal carboxylic acid. A strong absorption band was observed at $1080 \mathrm{~cm}^{-1}$, representing the C-O stretching of the ethylene glycol monomers [17]. The absence of representative peaks of S-H group (in the 2500-2600 $\mathrm{cm}^{-1}$ region, data not shown) indicates the fact that PEG layer is attached to AuNPs via Au-S bond. For PEGAuNPs-afatinib, it displays the mainly characteristic peaks at $1640 \mathrm{~cm}^{-1}$ due to the reaction of secondary amine into a stable imide $(\mathrm{C}=\mathrm{N})$ linkage [37]. Thus, the characterization indicates the formation of stable and well-dispersed PEGAuNPs-afatinib.

The afatinib conjugation efficiency was confirmed through the Protein Tyrosine Kinase Assay and determined to be $26 \pm 2 \%$ (by subtracting the unbound afatinib in the supernatant solution). Therefore, the final concentration of afatinib conjugated with PEGAuNPs was determined to be $3.6 \pm 0.6 \mu \mathrm{M}$.

The in vitro controlled release experiment of afatinib alone and afatinib conjugated with PEGAuNPs were investigated, as shown in Figure 3. The assay was performed through dialysis using a regenerated cellulose membrane with an initial afatinib concentration of $4.1 \mu \mathrm{M}$, in PBS $0.01 \mathrm{nM}$ at $37^{\circ} \mathrm{C}$ for 72 hours. By comparing the release profiles of afatinib, a higher release from afatinib alone was detected when compared with the afatinib release from the PEGAuNPs-afatinib conjugates (Figure 3). It was observed that $60 \%$ of the amount of afatinib was released after 6 hours compared to only $15 \%$ of afatinib release for PEGAuNPsAfatinib (Figure 3). After 27 hours, the amount of afatinib released from PEGAuNPs is $20 \%$, in contrast to almost all of afatinib being released when in its free form (Figure 3). The amount of afatinib released from PEGAuNPs after 72 hours of incubation remains constant and can occur due to the low bond-dissociation energy for removing successive sulphur atoms from gold nanoparticles (data not shown).

These results are in accordance with the fact that EDC/NHSS coupled reaction is highly efficient [35]. The sulfo-NHS-ester complex intermediate reacted, creating a stable imine linkage with the amine nucleophile 
secondary (afatinib) and, therefore, linkages do not readily break down, justifying the observed slow release of afatinib from conjugated PEGAuNPs [37].

LSCM technique was used to image the pancreatic (S2-013) and NSCLC cancer cells (A549) incubated with PEGAuNPs. Figure 4 shows the transmission image of the cancer cells that were incubated with PEGAuNPs for 2 hours. After the period of incubation with $1 \mathrm{nM}$ PEGAuNPs, the internalization of NPs was detected (Figure 4) and a higher contrast signal is detected in treated cancer cells compared with untreated cells (control). According to Silvia et al., nanoparticles are internalized by cancer cells even after a few minutes of incubation [9]. This fact is observed by an increase of the reflectance and transmission signal from cancer cells incubated with PEGAuNPs compared to the control cells. Also, an accumulation of the PEGAuNPs is observed in endocytic vesicles at the cell cytoplasm [9].

In order to evaluate the potential contribution of conjugated PEGAuNPs with afatinib to cytotoxicity, pancreatic S2-013 and NSCLC A549 cells, both with overexpression of EGFR, HER2 and HER3 [38, 39], were incubated with PEGAuNPs, PEGAuNPs-afatinib and afatinib alone for 72 hours. Afatinib was tested from concentrations ranging 0.026 to $0.500 \mu \mathrm{M}$. Additional concentrations were also tested with no enhancement of the afatinib toxicity being observed (data not shown). Alterations in cell survival following incubation with PEGAuNPs was evaluated using the SRB assay, and results show that, at concentrations up to $1.5 \mathrm{nM}$, PEGAuNPs do not induce toxicity on either cell line, following 72 hours incubation, indicating that the particles are biocompatible (data not shown). The influence of afatinib alone and in conjugation with PEGAuNPs on the cell survival and on the cell growth of both cell lines was also studied by the SRB assay and the $\mathrm{IC}_{50}$ and $\mathrm{GI}_{50}$ values $(\mathrm{p}<0.05)$ determined. Cells were incubated in media at different concentrations of afatinib (0.026 to $0.500 \mu \mathrm{M})$ and cell survival analyzed. When compared with afatinib alone, PEGAuNPsafatinib significantly inhibit cell survival for both cancer cells, with A549 displaying the highest sensitivity (Figure $5 \mathrm{~A}$ and Figure $5 \mathrm{C}$ ). For NSCLC line, a significant inhibition of cell survival is observed with afatinib concentrations between 0.066 to $0.500 \mu \mathrm{M}$.

The pancreatic cancer cell line used, S2-013, is more resistant to both PEGAuNPs-afatinib and afatinib alone, when compared to the A549 cells. Cell growth was significantly inhibited, when afatinib is conjugated with PEGAuNPs and for concentrations ranging from 0.132 to $0.369 \mu \mathrm{M}$.

The concentrations of afatinib alone inhibiting cell survival in $50 \%\left(\mathrm{IC}_{50}\right.$ values) were determined to be $0.50 \pm$ 0.02 and $0.87 \pm 0.04 \mu \mathrm{M}$ for S2-013 and A549s, respectively (Table 3). Comparing the $\mathrm{IC}_{50}$ of afatinib alone 
and PEGAuNPs-afatinib it is possible to observe significant changes. Results indicate that 5 times more afatinib alone is necessary to inhibit S2-013 cell survival in 50\% than PEGAuNPs-afatinib ( IC $_{50}$ of $0.50 \pm 0.02$ and $0.103 \pm 0.001$, respectively). Regarding the A549 cells, a concentration almost 20 times higher of afatinib alone is required than PEGAuNPs-afatinib to induce the same degree of cell survival inhibition $\left(\mathrm{IC}_{50}\right.$ of $0.87 \pm 0.04$ and $0.044 \pm 0.001$, respectively), as seen in Figure 5 and Table 3.

The same trend is observed when analyzing inhibition of cell growth in response to afatinib alone and PEGAuNPs-afatinib. For the S2-013s, the $\mathrm{GI}_{50}$ concentration lower for the PEGAuNPs-afatinib than that for afatinib alone $(0.09 \pm 0.01$ and $0.30 \pm 0.05 \mu \mathrm{M}$, respectively). Regarding A549 cells, the efficacy of PEGAuNPs-afatinib to inhibit cell growth is, also, more pronounced than that of afatinib alone $(0.039 \pm 0.001$ and $0.75 \pm 0.02 \mu \mathrm{M}$, respectively. Therefore, both cell survival $\left(\mathrm{IC}_{50}\right)$ and cell growth inhibition $\left(\mathrm{GI}_{50}\right)$ results indicate that PEGAuNPs-afatinib is approximately 5 and 20 times more potent than afatinib alone in S2-013 and A549 cells, respectively, corroborating our hypothesis that the afatinib effect is enhanced by the cellular uptake of afatinib conjugated with PEGAuNPs. As mentioned above, these experiments were performed using cell lines that overexpress several ErbB family members, particularly of EGFR and HER2 and, to a lesser extent, HER3 $[38,39]$. In addition to this, it may be interesting to investigate how the cell growth inhibition effect of the afatinib conjugated with PEGAuNPs would be observed in other cell lines with a range of different expression levels of the ErbB family members.

\section{Conclusions}

In summary, this work reports the preparation of afatinib-conjugated functionalized gold nanoparticles for targeted therapy of Pancreatic and Non-Small Cell Lung cancers. The results demonstrated the efficacy of PEGAuNPs-afatinib internalization on cancer cells, and the enhancement of afatinib antitumor activity when conjugated in these nanosystems. The cytotoxicity results indicated that afatinib-conjugated PEGAuNPs inhibit cell growth of lung and pancreatic cancer cell lines more efficiently than the afatinib drug alone. Our findings indicate that the use of afatinib-conjugated PEGAuNPs is a promising antitumour vector for cancer therapies. Future work will be needed to clarify the uptake mechanisms of PEGAuNPs-afatinib.

\section{Acknowledgements}


This work was supported by financial support by TRANSCAN-FCT (research project

TRANSCAN/0001/2012) and Portuguese Cancer League. We gratefully acknowledge Prof. Michael A.

Hollingsworth (University of Nebraska Medical Center - Omaha, USA) for kindly providing the human pancreatic cell lines (S2-013). We gratefully acknowledge Dr George DD Jones (University of Leicester, UK) for kindly providing the human NSCLC cell line A549. We would like to thank Dr. Paula Sampaio for the collaboration with confocal work analysis.

IPATIMUP integrates the i3S Research Unit, which is partially supported by FCT, the Portuguese Foundation for Science and Technology. Salary support to GMA from FCT Program 2013, POPH - QREN Type 4.2, European Social Fund and Portuguese Ministry of Science and Technology (MCTES).

\section{References}

1. Dreaden EC, Austin LA, Mackey MA, El-Sayed MA. Size matters: gold nanoparticles in targeted cancer drug delivery. Therapeutic delivery 2012;3(4):457-78.

2. Jain PK, El-Sayed IH, El-Sayed MA. Au nanoparticles target cancer. Nano Today 2007;2(1):18-29.

3. Xiao Z, Levy-Nissenbaum E, Alexis F, Lupták A, Teply BA, Chan JM, et al. Engineering of Targeted Nanoparticles for Cancer Therapy Using Internalizing Aptamers Isolated by Cell-Uptake Selection. ACS Nano 2012 2012/01/24;6(1):696-704.

4. Unfried K, Albrecht C, Klotz L-O, Von Mikecz A, Grether-Beck S, Schins RPF. Cellular responses to nanoparticles: Target structures and mechanisms. Nanotoxicology 2007;1(1):52-71.

5. Kim JA, Aberg C, Salvati A, Dawson KA. Role of cell cycle on the cellular uptake and dilution of nanoparticles in a cell population. Nat Nano 2012 01//print; 7(1):62-68.

6. Nichols J, Bae Y. Nanotechnology for Cancer Treatment: Possibilities and Limitations. In: Bae YH, Mrsny RJ, Park K, eds. Cancer Targeted Drug Delivery: Springer New York 2013:37-56.

7. Dykman LA, Khlebtsov NG. Uptake of Engineered Gold Nanoparticles into Mammalian Cells. Chemical Reviews 2014 2014/01/22;114(2):1258-88.

8. Jain S, Hirst DG, O'Sullivan JM. Gold nanoparticles as novel agents for cancer therapy. Br J Radiol 2012 Feb;85(1010):101-13.

9. Coelho SC, Rocha S, Juzenas P, Sampaio P, Almeida GM, Silva FS, et al. Gold nanoparticle deliveryenhanced proteasome inhibitor effect in adenocarcinoma cells. Expert opinion on drug delivery 2013;10(10):1345-52.

10. Han G, Ghosh P, Rotello VM. Functionalized gold nanoparticles for drug delivery. Nanomedicine (Lond) $2007 \mathrm{Feb} ; 2(1): 113-23$.

11. Rosi NL, Giljohann DA, Thaxton CS, Lytton-Jean AKR, Han MS, Mirkin CA. Oligonucleotide-Modified Gold Nanoparticles for Intracellular Gene Regulation. Science 2006 May 19, 2006;312(5776):1027-30.

12. Comenge J, Sotelo C, Romero F, Gallego O, Barnadas A, Parada TG, et al. Detoxifying antitumoral drugs via nanoconjugation: the case of gold nanoparticles and cisplatin. PloS one 2012;7(10):e47562.

13. Kao HW, Lin YY, Chen CC, Chi KH, Tien DC, Hsia CC, et al. Biological characterization of cetuximabconjugated gold nanoparticles in a tumor animal model. Nanotechnology $2014 \mathrm{Jul}$ 25;25(29):295102.

14. Li J, Gupta S, Li C. Research perspectives: gold nanoparticles in cancer theranostics. Quantitative Imaging in Medicine and Surgery 2013 11/28/received

12/09/accepted;3(6):284-91.

15. Coelho SC, Rocha S, Pereira MC, Juzenas P, Coelho MAN. Enhancing Proteasome-Inhibitor Effect by Functionalized Gold Nanoparticles. Journal of biomedical nanotechnology 2014 //;10(4):717-23. 
16. Bartczak D, Kanaras AG. Preparation of Peptide-Functionalized Gold Nanoparticles Using One Pot EDC/Sulfo-NHS Coupling. Langmuir 2011 2011/08/16;27(16):10119-23.

17. Tsai DH, Davila-Morris M, DelRio FW, Guha S, Zachariah MR, Hackley VA. Quantitative determination of competitive molecular adsorption on gold nanoparticles using attenuated total reflectance-Fourier transform infrared spectroscopy. Langmuir 2011 Aug 2;27(15):9302-13.

18. Qian Y, Qiu M, Wu Q, Tian Y, Zhang Y, Gu N, et al. Enhanced cytotoxic activity of cetuximab in EGFRpositive lung cancer by conjugating with gold nanoparticles. Sci Rep 2014 12/15/online;4.

19. Shukla R, Bansal V, Chaudhary M, Basu A, Bhonde RR, Sastry M. Biocompatibility of gold nanoparticles and their endocytotic fate inside the cellular compartment: a microscopic overview. Langmuir 2005 Nov 8;21(23):10644-54.

20. Connor EE, Mwamuka J, Gole A, Murphy CJ, Wyatt MD. Gold nanoparticles are taken up by human cells but do not cause acute cytotoxicity. Small 2005 Mar;1(3):325-7.

21. Ali MRK, Panikkanvalappil SR, El-Sayed MA. Enhancing the Efficiency of Gold Nanoparticles Treatment of Cancer by Increasing Their Rate of Endocytosis and Cell Accumulation Using Rifampicin. Journal of the American Chemical Society 2014 2014/03/26;136(12):4464-67.

22. Chithrani BD, Ghazani AA, Chan WC. Determining the size and shape dependence of gold nanoparticle uptake into mammalian cells. Nano Lett 2006 Apr;6(4):662-8.

23. Pelgrift RY, Friedman AJ. Nanotechnology as a therapeutic tool to combat microbial resistance. Advanced Drug Delivery Reviews 2013 11/30/;65(13-14):1803-15.

24. Ioannou N, Dalgleish AG, Seddon AM, Mackintosh D, Guertler U, Solca F, et al. Anti-tumour activity of afatinib, an irreversible ErbB family blocker, in human pancreatic tumour cells. British journal of cancer 2011 Nov 8;105(10):1554-62.

25. Tsai YC, Yeh $\mathrm{CH}$, Tzen KY, Ho PY, Tuan TF, Pu YS, et al. Targeting epidermal growth factor receptor/human epidermal growth factor receptor 2 signalling pathway by a dual receptor tyrosine kinase inhibitor afatinib for radiosensitisation in murine bladder carcinoma. European journal of cancer (Oxford, England : 1990) 2013 Apr;49(6):1458-66.

26. Awada AH, Dumez $\mathrm{H}$, Hendlisz A, Wolter P, Besse-Hammer T, Uttenreuther-Fischer $\mathrm{M}$, et al. Phase I study of pulsatile 3-day administration of afatinib (BIBW 2992) in combination with docetaxel in advanced solid tumors. Investigational new drugs 2013 Jun;31(3):734-41.

27. Li D, Ambrogio L, Shimamura T, Kubo S, Takahashi M, Chirieac LR, et al. BIBW2992, an irreversible EGFR/HER2 inhibitor highly effective in preclinical lung cancer models. Oncogene 2008 04/14;27(34):4702-11.

28. D'Arcangelo M, Hirsch FR. Clinical and comparative utility of afatinib in non-small cell lung cancer. Biologics : targets \& therapy 2014;8:183-92.

29. Yang JC-H, Wu Y-L, Schuler M, Sebastian M, Popat S, Yamamoto N, et al. Afatinib versus cisplatin-based chemotherapy for EGFR mutation-positive lung adenocarcinoma (LUX-Lung 3 and LUX-Lung 6): analysis of overall survival data from two randomised, phase 3 trials. The Lancet Oncology 2015 2//;16(2):141-51.

30. Li D, Ambrogio L, Shimamura T, Kubo S, Takahashi M, Chirieac LR, et al. BIBW2992, an irreversible EGFR/HER2 inhibitor highly effective in preclinical lung cancer models. Oncogene 2008 Aug 7;27(34):4702-11.

31. Chen X, Zhu Q, Zhu L, Pei D, Liu Y, Yin Y, et al. Clinical perspective of afatinib in non-small cell lung cancer. Lung cancer (Amsterdam, Netherlands) 2013 Aug;81(2):155-61.

32. Guan SS, Chang J, Cheng CC, Luo TY, Ho AS, Wang CC, et al. Afatinib and its encapsulated polymeric micelles inhibits HER2-overexpressed colorectal tumor cell growth in vitro and in vivo. Oncotarget 2014 Jul 15;5(13):4868-80.

33. Turkevich J, Stevenson PC, Hillier J. A study of the nucleation and growth processes in the synthesis of colloidal gold. Discussions of the Faraday Society 1951;11:55-75.

34. Kimling J, Maier M, Okenve B, Kotaidis V, Ballot H, Plech A. Turkevich Method for Gold Nanoparticle Synthesis Revisited. The Journal of Physical Chemistry B 2006;110(32):15700-07.

35. Hermanson GT. Chapter 3 - Zero-Length Crosslinkers. In: Hermanson GT, ed. Bioconjugate Techniques (Second Edition). New York: Academic Press 2008:213-33.

36. Baptista P, Doria G, Henriques D, Pereira E, Franco R. Colorimetric detection of eukaryotic gene expression with DNA-derivatized gold nanoparticles. Journal of Biotechnology 2005 9/23/;119(2):111-17.

37. Hermanson GT. Chapter 25 - Modification with Synthetic Polymers. In: Hermanson GT, ed. Bioconjugate Techniques (Second Edition). New York: Academic Press 2008:936-60. 
38. Frolov A, Schuller K, Tzeng CW, Cannon EE, Ku BC, Howard JH, et al. ErbB3 expression and dimerization with EGFR influence pancreatic cancer cell sensitivity to erlotinib. Cancer Biol Ther 2007 Apr;6(4):548-54.

39. Nakamura H, Takamori S, Fujii T, Ono M, Yamana H, Kuwano M, et al. Cooperative cell-growth inhibition by combination treatment with ZD1839 (Iressa) and trastuzumab (Herceptin) in non-small-cell lung cancer. Cancer Letters 2005 12/8/;230(1):33-46.

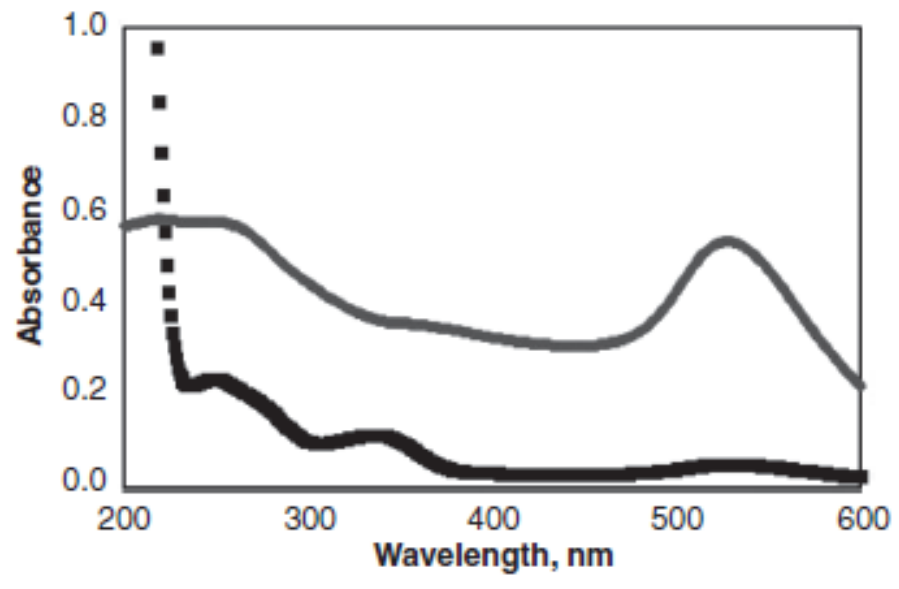

Figure 1. UV-vis absorption spectra of PEGAuNPs (gray line) and PEGAuNPs-afatinib (black line).

PEGAUNPS: Pegylated gold nanoparticles.
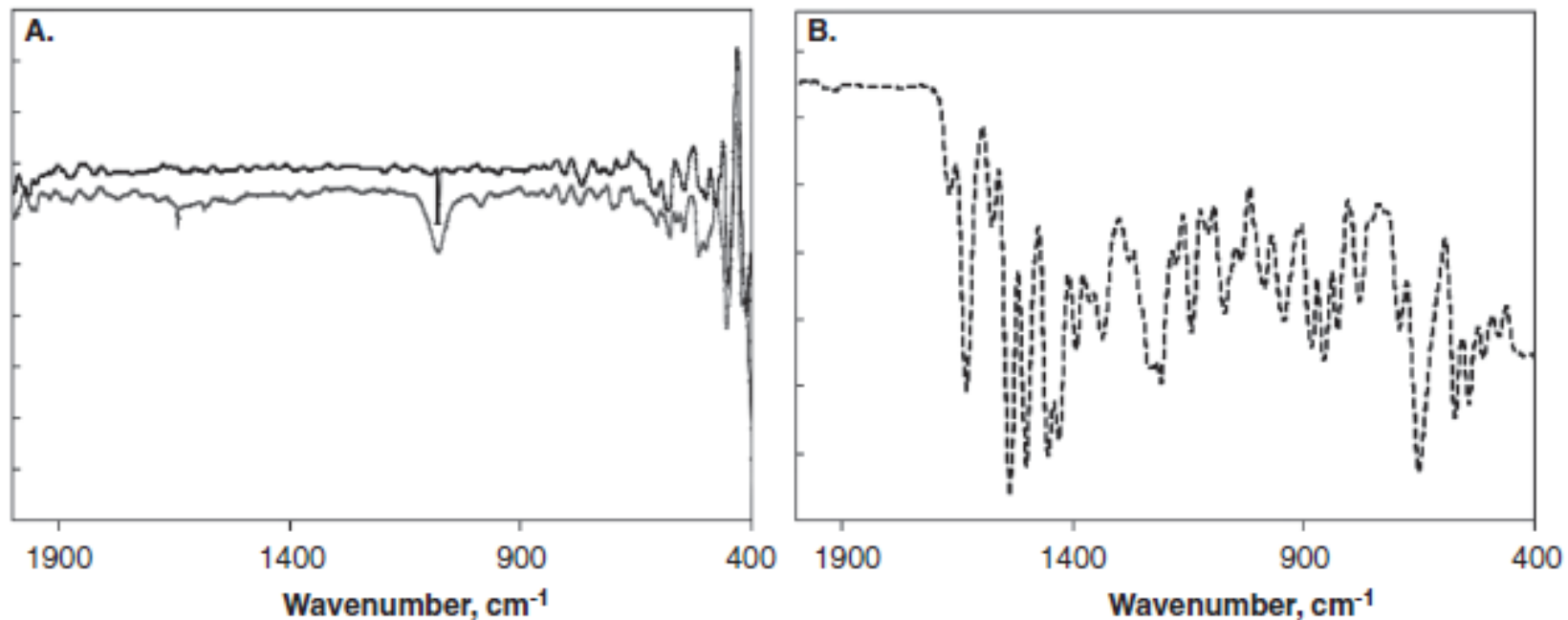

Figure 2. FIR spectra of (A) PEGAuNPs (black line) and PEGAuNPs-afatinib (gray line); (B) afatinib alone (black dots). The spectra were shifted for a better visualization.

PEGAUNPS: Pegylated gold nanoparticles. 


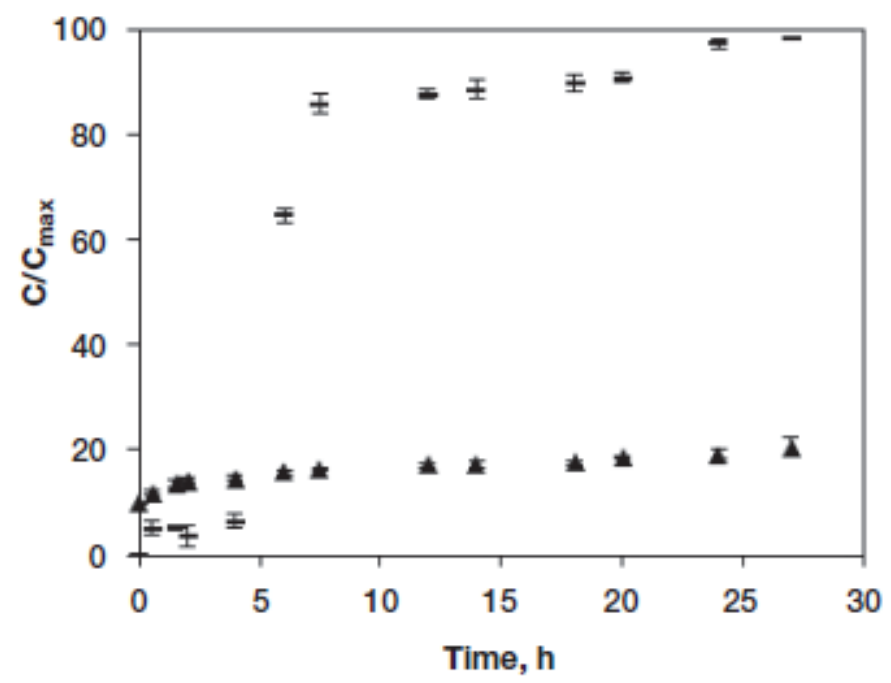

Figure 3. In vitro release profiles of afatinib alone (-) and PEGAuNPs-afatinib $(\boldsymbol{\Delta})$ in PBS at $37^{\circ} \mathrm{C}$. $\mathrm{C}_{\max }$ corresponds to the total amount of afatinib added. Results are shown as mean \pm SEM of three independent experiments.

PEGAUNPS: Pegylated gold nanoparticles.

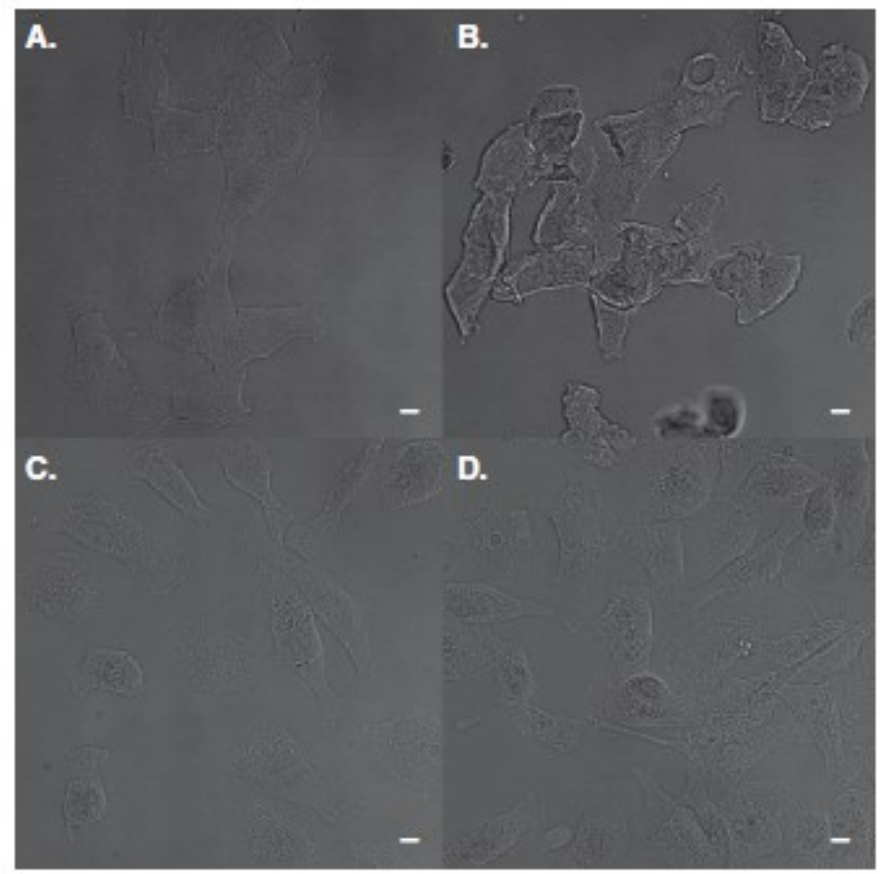

Figure 4. Confocal transmission images of A549 (A, B), S2-013 (C, D) cells at $2 \mathrm{~h}$ of incubation. The cells were incubated with PEGAuNPs $1 \mathrm{nM}(\mathrm{B}, \mathrm{D})$; the control untreated cells (A, C). Scale bar is $10 \mu \mathrm{m}$.

PEGAUNPS: Pegylated gold nanoparticles. 
A.

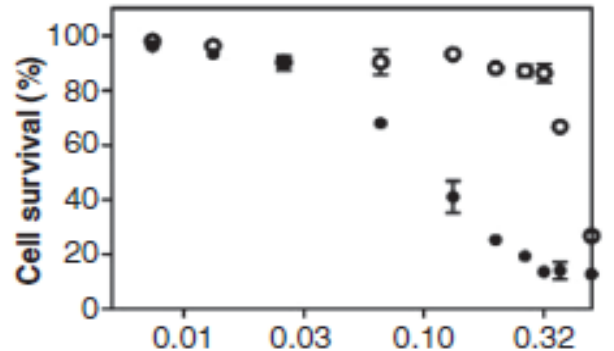

$\log$ (concentration of afatinib) $(\mu \mathrm{M})$

C.

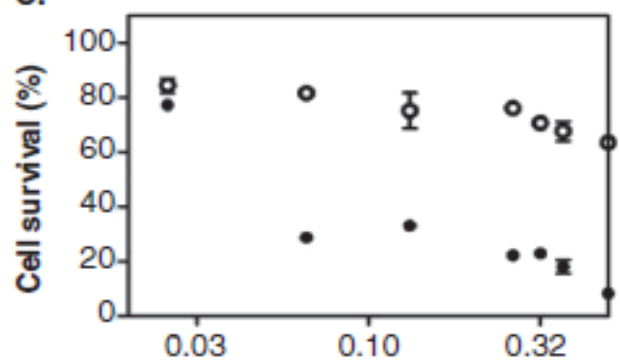

Log (concentration of afatinib) $(\mu \mathrm{M})$
B.

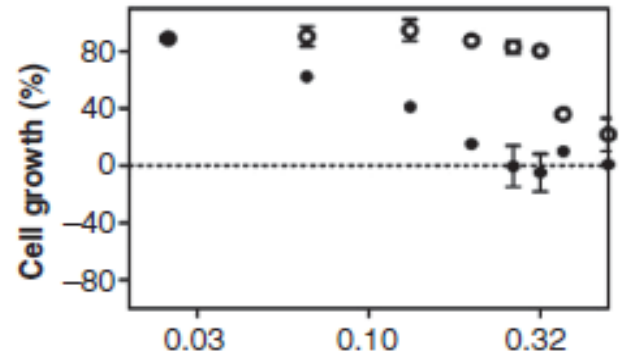

Log (concentration of afatinib) $(\mu \mathrm{M})$

D.

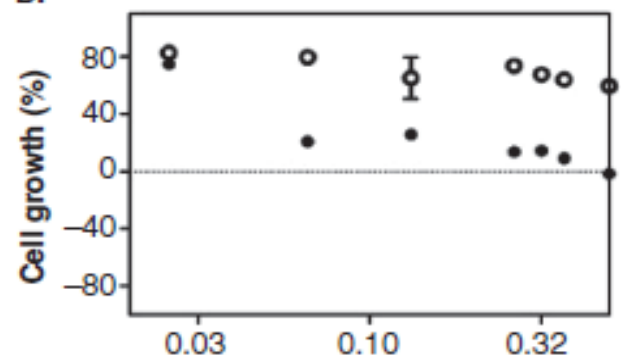

Log (concentration of afatinib) $(\mu \mathrm{M})$

Figure 5. Effect of the PEGAuNPs-afatinib $(\bullet)$ and afatinib alone $(O)$ on the cell survival $\left(I_{50}\right.$ determination) $($ A, C) and on cell growth ( $\mathrm{Gl}_{50}$ determination) (C, D) of S2-013 (A, B) and A549 (C, D) cells.

PEGAUNPS: Pegylated gold nanoparticles.

Table 1. Hydrodynamic mean diameter, polydispersity index (Pdl) and zeta potential of gold nanoparticles.

\begin{tabular}{|c|c|c|c|c|c|}
\hline Sample & Diameter (nm) & Pdl & Zeta potential (mV) & AuNPs concentration (nM) & Afatinib concentration ( $\mathrm{nM}$ ) \\
\hline PEGAuNPS & $41 \pm 1$ & 0.4 & $-39 \pm 3$ & 14.02 & - \\
\hline PEGAuNPs-afatinib & $41 \pm 3$ & 0.6 & $-35 \pm 4$ & 4.60 & 3.61 \\
\hline
\end{tabular}

PEGAUNPS: Pegylated gold nanoparticles.

Table 2. Half-maximal inhibitory concentration $\left(\mathrm{IC}_{50}\right)$ and effect of afatinib alone and PEGAuNPs-afatinib on the growth inhibition $\left(\mathrm{Gl}_{50}\right)$ of the pancreatic cell lines S2-013 and NSCLL A549 cells.

\begin{tabular}{llllll}
\hline & \multicolumn{2}{c}{ S2-013 } & & \multicolumn{2}{c}{ A549 } \\
\cline { 2 - 3 } \cline { 5 - 6 } & PEGAuNPs-afatinib & Afatinib & & PEGAuNPs-afatinib & Afatinib \\
\hline $\mathrm{IC}_{50}(\mu \mathrm{M})$ & $0.103 \pm 0.001$ & $0.497 \pm 0.023$ & & $0.044 \pm 0.001$ & $0.874 \pm 0.036$ \\
$\left.\mathrm{Gl}\right|_{50}(\mu \mathrm{M})$ & $0.087 \pm 0.010$ & $0.390 \pm 0.049$ & & $0.039 \pm 0.001$ & $0.746 \pm 0.023$ \\
\hline
\end{tabular}

PEGAUNPS: Pegylated gold nanoparticles.

Table 3. Effect of afatinib alone and PEGAuNPs-afatinib on the cell-cycle distribution of cancer S2-013 and A549 cell lines.

\begin{tabular}{|c|c|c|c|c|}
\hline Cell line/treatment & Sub-G1 & G0/G1 & $\mathbf{S}$ & $\mathrm{G} 2 / \mathrm{M}$ \\
\hline \multicolumn{5}{|l|}{$52-013$} \\
\hline Control & $7.39 \pm 0.490$ & $67.0 \pm 1.91$ & $13.5 \pm 0.710$ & $10.1 \pm 0.590$ \\
\hline PEGAuNPS-afatinib & $7.19 \pm 0.530$ & $57.9 \pm 6.01$ & $20.6 \pm 6.01$ & $11.5 \pm 0.490$ \\
\hline Afatinib alone & $11.7 \pm 1.77$ & $42.8 \pm 8.27$ & $22.0 \pm 4.24$ & $22.6 \pm 10.8$ \\
\hline \multicolumn{5}{|l|}{ A549 } \\
\hline Control & $6.98 \pm 1.36$ & $54.8 \pm 3.07$ & $20.1 \pm 1.54$ & $17.1 \pm 2.97$ \\
\hline PEGAuNPs-afatinib & $2.16 \pm 0.0500$ & $65.5 \pm 2.83$ & $27.2 \pm 1.41$ & $4.06 \pm 1.44$ \\
\hline Afatinib alone & $6.18 \pm 0.170$ & $62.8 \pm 1.39$ & $16.7 \pm 0.35$ & $13.6 \pm 1.57$ \\
\hline
\end{tabular}

PEGAUNPS: Pegylated gold nanoparticles. 